\begin{tabular}{|c|c|c|}
\hline \multirow{3}{*}{$\begin{array}{r}\text { Case Reports in } \\
\text { Gastroenterology }\end{array}$} & \multirow{2}{*}{\multicolumn{2}{|c|}{ Case Rep Gastroenterol 2014;8:353-357 }} \\
\hline & & \\
\hline & $\begin{array}{l}\text { DOI: } 10.1159 / 000369249 \\
\text { Publisnea onine:TNovember 11, } 2014\end{array}$ & $\begin{array}{l}\text { ○ } 2014 \text { S. Karger AG, Basel } \\
\text { 1662-0631/14/0083-0353 } \$ 39.50 / 0 \\
\text { www.karger.com/crg }\end{array}$ \\
\hline & \multicolumn{2}{|c|}{$\begin{array}{l}\text { This is an Open Access article licensed under the terms of the Creative Commons } \\
\text { Attribution-NonCommercial } 3.0 \text { Unported license (CC BY-NC) (www.karger.com/OA } \\
\text { license), applicable to the online version of the article only. Distribution permitted for non } \\
\text { commercial purposes only. }\end{array}$} \\
\hline
\end{tabular}
commercial purposes only.

\title{
Signet Ring Cell Carcinoma of the Extrahepatic Bile Duct Diagnosed by Preoperative Biopsy: A Case Report
}

\author{
Emiri Kita ${ }^{a}$ Akiko Tsujimoto $^{a} \quad K^{2}$ azuyoshi Nakamura ${ }^{a}$ Kentaro Sudo ${ }^{a}$ \\ Taro Hara $^{a}$ Osamu Kainuma $^{\mathrm{b}}$ Hiroshi Yamamoto $^{\mathrm{b}}$ Makiko Itami $^{\mathrm{c}}$ \\ Taketo Yamaguchi ${ }^{\mathrm{a}}$ \\ Departments of a Gastroenterology, ${ }^{\text {b }}$ Surgery and ${ }^{\mathrm{C}}$ Clinical Pathology, Chiba Cancer Center, \\ Chiba, Japan
}

\section{Key Words}

Bile duct carcinoma . Signet ring cell carcinoma ·aundice

\begin{abstract}
A 73-year-old woman was admitted because of obstructive jaundice. Computed tomography revealed a stricture in the lower bile duct with enhanced bile duct wall. Endoscopic retrograde cholangiopancreatography (ERCP) revealed a tapering stenosis at the lower bile duct. Transpapillary histological biopsy using biopsy forceps through ERCP was performed; the diagnosis of signet ring cell carcinoma (SRCC) of the bile duct was established. Regional lymph node enlargement and distant metastases were not detected on diagnostic imaging. Pancreaticoduodenectomy with pylorus preservation was performed. Histological examination of the resected specimen confirmed SRCC of the extrahepatic bile duct coexisting with adenocarcinoma $(A D C)$ of the extrahepatic bile duct with negative resection margins. However, tumor cells directly invaded the pancreatic parenchyma and the muscle layer of the duodenum, prompting us to administer adjuvant chemotherapy to the patient, with no sign of tumor recurrence at 1-year follow-up. Almost all tumors originating from the extrahepatic bile duct are ADC and other histological variants are rare. Of these, SRCC is extremely rare and only four cases have been reported. Furthermore, to the best of our knowledge, this is the first case report regarding the preoperative diagnosis of SRCC of the bile duct. Current reports indicate that younger age and Asian ethnicity are the clinical features of SRCC of the extrahepatic bile duct. Immunohistochemical staining of CK7, CK20 and MUC2 may be useful for predicting prognosis. Chemotherapy has not resulted in increased survival rates and only surgical resection currently serves as a curative treatment.

(c) 2014 S. Karger AG, Basel
\end{abstract}

Taketo Yamaguchi

Department of Gastroenterology, Chiba Cancer Center

666-2 Nitonacho, Chuo-ku, Chiba 260-8717 (Japan)

E-Mail tyamaguchi@chiba-cc.jp 
Kita et al.: Signet Ring Cell Carcinoma of the Extrahepatic Bile Duct Diagnosed by Preoperative Biopsy: A Case Report

\section{Introduction}

Carcinoma of the bile duct accounts for approximately $2 \%$ of all carcinomas and $0.5 \%$ of all carcinomas at autopsy $[1,2]$. The peak incidence commonly occurs in the seventh decade of life, and patients are usually over 65 years of age [3]. Histopathologically, almost all tumors affecting the bile duct are well to moderately differentiated adenocarcinomas (ADCs), whereas other histological variants are less frequent; of these, signet ring cell carcinoma (SRCC) is extremely rare. This report presents the first case of SRCC of the extrahepatic bile duct that was successfully diagnosed by preoperative biopsy through endoscopic retrograde cholangiopancreatography (ERCP). The clinicopathological characteristics of the condition are also discussed.

\section{Case Report}

A 73-year-old woman was admitted to our hospital because of obstructive jaundice. Enhanced computed tomography revealed a hypervascular mass in the lower common bile duct and a stricture accompanied by a proximal dilatation of the bile duct (fig. 1). ERCP revealed stenosis at the lower bile duct. Transpapillary histological biopsy using forceps biopsy through ERCP was performed; a diagnosis of SRCC of the bile duct was then established (fig. 2). Regional lymph node enlargement and distant metastases were not detected on diagnostic imaging; thus, subsequent pancreaticoduodenectomy with pylorus preservation was performed. Histological examination of the resected specimen revealed a thickened wall with a whitish tumor with a size of $2.0 \times 2.0 \times 1.7 \mathrm{~cm}$ at the lower bile duct upon gross inspection.

Microscopically, the tumor was primarily composed of SRCC, partially coexisting with poorly differentiated ADC. Tumor cells contained mucin with vesicular nuclei and prominent nucleoli (fig. 3a), infiltrating the pancreatic parenchyma and involving the muscularis propria of the duodenum. None of the lymph nodes presented metastases. Immunohistochemical staining showed tumor cells that were positive for CK7 (fig. 3b), but negative for both CK20 (fig. 3c) and MUC2 (fig. 3d). Finally, the tumor was diagnosed as T3N0M0 stage III according to the International Union Against Cancer TNM classification, and the patient received adjuvant chemotherapy using cisplatin + gemcitabine without signs of tumor recurrence at 1-year follow-up.

\section{Discussion}

SRCC commonly occurs in the gastrointestinal tract, particularly in the stomach, and sometimes occurs in the gallbladder or ampulla. However, SRCC of the biliary tract is extremely rare, and the clinicopathological characteristics are unclear. Previously, only four cases of primary SRCC of the extrahepatic bile duct have been reported in the literature. Most of the reports were from Asian countries ( 4 out of 5 patients), and from these reports and the present case, $60 \%$ were male. The mean age was 61.5 years (range $42-78$ years), which was younger than that observed in common biliary tract cancer. Jaundice was the most common symptom ( 4 out of 5 patients).

Since SRCC progresses rapidly, it often results in poor prognosis. Among the previous four cases of biliary SRCC, two underwent surgical intervention (one patient underwent surgery and the other had surgery with adjuvant chemoradiation), and no signs of recur- 
Kita et al.: Signet Ring Cell Carcinoma of the Extrahepatic Bile Duct Diagnosed by Preoperative Biopsy: A Case Report

rence were reported (table 1). The two patients who had unresectable advanced cancer died within 3 months (one received chemotherapy and the other was under observation). Only surgical resection has been suggested as a curative treatment, and neither chemotherapy nor radiotherapy appeared to show survival benefits in these patients.

The histological origin of SRCC in the extrahepatic bile duct remains elusive. To date, two theories involving the periampullary area have been proposed; one states that SRCC develops on the ectopic gastric mucosa $[4,5]$, and the other states that the gastric-type metaplastic change of duodenal epithelium may be the origin of SRCC [5-7]. However, the present case showed neither ectopic gastric mucosa nor metaplastic changes in the surgical specimen. One more possible origin of SRCC is from ADC that marginally coexists in the transitional zone. We speculate that SRCC in this case had dedifferentiated from the preexisting ADC.

Roh et al. [8] demonstrated the association between immunohistochemical markers and the prognosis of SRCC of the extrahepatic bile duct. Carcinoma immunoprofiling has identified the intestinal and the pancreatobiliary type of SRCC. The intestinal type is negative for CK7, but positive for CK20/MUC2, which is strongly associated with better prognosis. On the other hand, the pancreatobiliary type is positive for CK7 but negative for CK20/MUC2 and has been associated with poorer prognosis [9]. The present case was positive for CK7, but negative for CK20/MUC2; therefore, the case was considered to be the pancreatobiliary type and was expected to have a poor prognosis. Although the patient had no evidence of recurrence at 1-year follow-up, the clinical course had to be closely monitored.

Pathological diagnosis of a malignant lesion is vital to the decision-making process of whether surgical resection or chemotherapy is the appropriate treatment. A pathological diagnosis is usually established after bile cytology, biliary brushing cytology or biliary biopsy. Previous studies have shown that the sensitivity of biliary biopsy is higher than other transpapillary sampling methods. This is the first case of SRCC in whom an accurate preoperative diagnosis could be made by using transpapillary bile duct biopsy. Although the immunochemical profile of this case suggested a poorer prognosis, correct preoperative diagnosis was helpful in the subsequent early-stage surgical resection and in improving the patient's prognosis. The clinicopathological features and prognosis of biliary SRCC remain unclear due to its rarity; therefore, more extensive investigations are warranted.

\section{Disclosure Statement}

The authors have no potential conflicts of interest.

\section{References}

1 Jarnagin WR, Shoup M: Surgical management of cholangiocarcinoma. Semin Liver Dis 2004;24:189-199.

-2 Akoad M, Jenkins R: Proximal biliary malignancy. Surg Clin North Am 2008;88:1409-1428.

3 Mosconi S, Beretta GD, Labianca R, Zampino MG, Gatta G, Heinemann V: Cholangiocarcinoma. Crit Rev Oncol Hematol 2009;69:259-270.

4 Gardner HA, Matthews J, Ciano PS: A signet-ring cell carcinoma of the ampulla of Vater. Arch Pathol Lab Med 1990;114:1071-1072.

5 Ramia JM, Mansilla A, Villar J, Muffak K, Garrote D, Ferron JA: Signet-ring cell carcinoma of the Vater's ampulla. JOP 2004;5:495-497.

-6 Akatsu T, Aiura K, Takahashi S: Signet-ring cell carcinoma of the ampulla of Vater: report of a case. Surg Today 2007;37:1110-1114.

7 Gao JM, Tang SS, Fu W, Fan R: Signet-ring cell carcinoma of ampulla of Vater: contrast-enhanced ultrasound findings. World J Gastroenterol 2009;15:888-891. 
Kita et al.: Signet Ring Cell Carcinoma of the Extrahepatic Bile Duct Diagnosed by Preoperative Biopsy: A Case Report

-8 Roh YH, Kim YH, Lee HW, Kim SJ, Roh MS, Jeon JS, Jung GJ: The clinicopathologic and immunochemical characteristics of ampulla of Vater carcinoma: the intestinal type is associated with a better prognosis. Hepatogastroenterology 2007;54:1641-1644.

-9 Fischer HP, Zhou H: Pathogenesis of carcinoma of the papilla of Vater. J Hepatobiliary Pancreat Surg 2004;11:301-309.

10 Hiraki M, Yakushiji H, Hashiguchi K, Harada S, Okada K, Goto Y, Ikeda H, Mori D, Tokonaga O, Miyazaki K: Signet ring cell carcinoma of the lower bile duct with rapid growth: report of a case. Hepatogastroenterology 2007;54:1922-1924.

11 Ogata S, Kimura A, Hatsuse K, Yamamoto J, Shimazaki H, Nakanishi K, Kawai T: Poorly differentiated adenocarcinoma with signet-ring cell carcinoma of the extrahepatic bile duct in a 42-year-old Japanese female: a case report. Acta Med Okayama 2010;64:63-65.

$\checkmark 12$ Lee EY, Kim C, Kim MJ, Park JY, Park SW, Song SY, Chung JB, Kim H, Bang S: Signet ring cell carcinoma of the extrahepatic bile duct. Gut Liver 2010;4:402-406.

13 Matsumoto T, Inoue S, Masuo K, Okamoto Y, Fukushima M, Wada M, Shimeno N, Kimoto N, Fujita M, Suginoshita Y, Okada A, Inokuma T, Imai Y: Signet ring cell carcinoma of the bile duct: a case report. Nihon Shokakibyo Gakkai Zasshi 2011;108:2042-2049.

Table 1. Reported cases of SRCC of the extrahepatic bile duct

\begin{tabular}{|c|c|c|c|c|c|c|}
\hline Case study & $\begin{array}{l}\text { Age, } \\
\text { years }\end{array}$ & Sex & $\begin{array}{l}\text { TNM } \\
\text { stage }\end{array}$ & Treatment & $\begin{array}{l}\text { Histo- } \\
\text { pathology }\end{array}$ & Outcome \\
\hline Hiraki et al., 2007 [10] & 78 & $\mathrm{~m}$ & - & chemotherapy & SRCC & 3 months \\
\hline Ogata et al., 2010 [11] & 42 & $\mathrm{f}$ & T4N1M0 & PD & $\mathrm{SRCC}+\mathrm{ADC}$ & alive \\
\hline Lee et al., 2010 [12] & 55 & $\mathrm{~m}$ & T3N1M0 & $\mathrm{PD}+\mathrm{CRT}$ & SRCC & alive \\
\hline Matsumoto et al., 2011 [13] & 72 & $\mathrm{~m}$ & T4N3M1 & none & SRCC & 3 months \\
\hline Present study & 73 & $\mathrm{f}$ & T3N0M0 & PD & SRCC + ADC & alive \\
\hline
\end{tabular}

CRT = Chemoradiation therapy; $\mathrm{PD}=$ pancreaticoduodenectomy.



Fig. 1. Enhanced computed tomography demonstrating a hypervascular mass in the lower common bile duct. 
Kita et al.: Signet Ring Cell Carcinoma of the Extrahepatic Bile Duct Diagnosed by Preoperative Biopsy: A Case Report

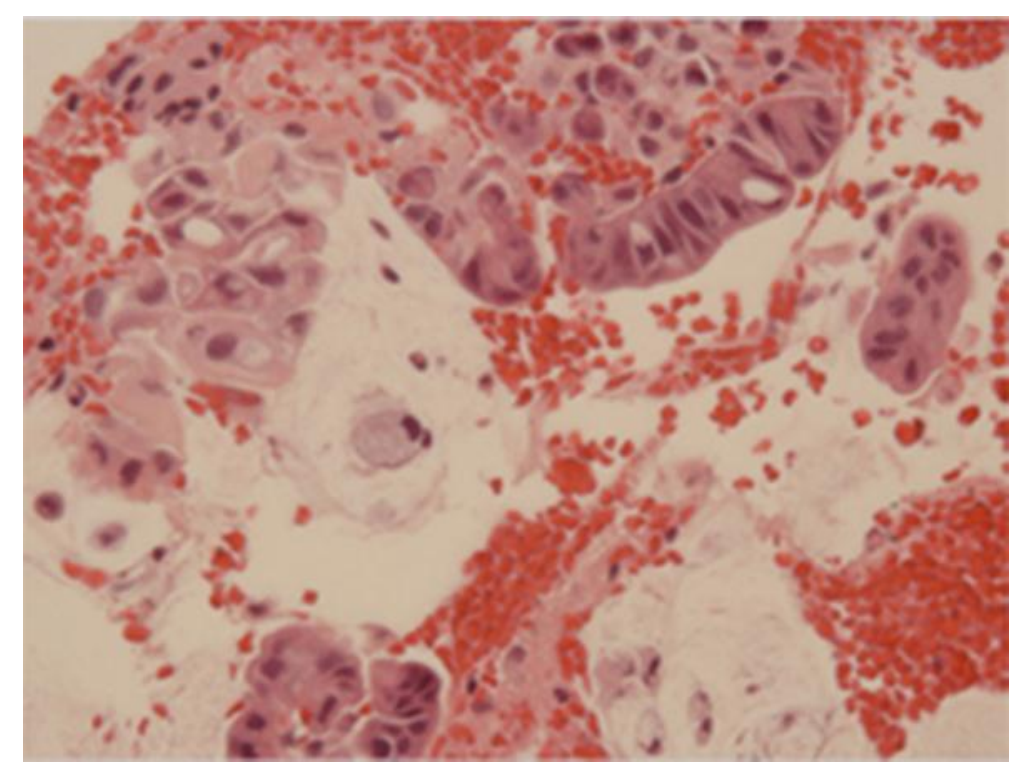

Fig. 2. The biopsy specimen contained abundant intracytoplasmic mucin and nuclei (H\&E staining, $\times 400)$.
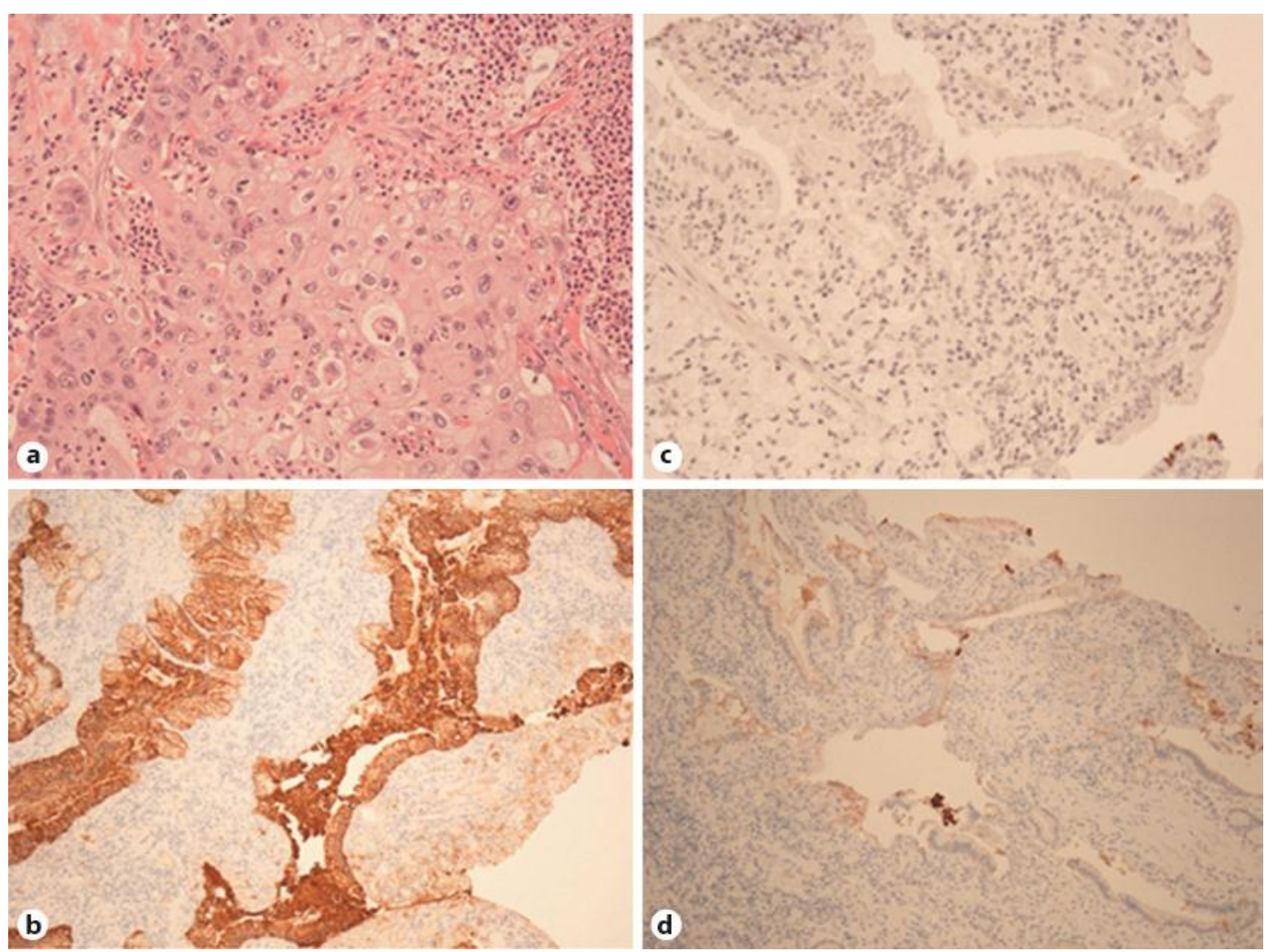

Fig. 3. a The tumor was histopathologically composed of SRCC and poorly differentiated ADC (H\&E staining, $\times 400)$. b-d Immunohistochemical findings for CK7 (b, ×100), CK20 (c, ×100) and MUC2 (d, ×100). 